\title{
Pulmonary Function Testing and Complications of Laparoscopic Bariatric Surgery
}

\author{
Astrid van Huisstede • Laser Ulas Biter • \\ Ronald Luitwieler • Manuel Castro Cabezas • \\ Guido Mannaerts • Erwin Birnie • Christian Taube • \\ Pieter S. Hiemstra • Gert-Jan Braunstahl
}

Published online: 21 March 2013

(C) Springer Science+Business Media New York 2013

gastric bypass). There were 53 complications ( 8 pulmonary, 27 surgical, 14 infectious, 4 other) in 50 patients $(10 \%)$. There were 35 re-admissions (7.2\%), and 17 relaparoscopies $(3.5 \%)$. Subjects with and without complications did not differ significantly with respect to demographics, weight, BMI, abdominal circumference or fat percentage. Subjects with complications had a significantly lower mean $\mathrm{FEV}_{1}$ (mean $86.9 \%$ predicted) and FVC (95.6\% predicted) compared to patients without complications (95.9\% predicted, $p=0.005$, and $100.1 \%$ predicted, $p=0.045$, respectively). After adjustment for age, gender, BMI, and smoking, abnormal spirometry value remained the single predictive covariable of postoperative

\footnotetext{
E. Birnie

Department of Statistics, Sint Franciscus Gasthuis, Kleiweg 500, 3045 PM Rotterdam, The Netherlands e-mail: e.birnie@sfg.nl
}

\author{
E. Birnie \\ Institute of Health Policy and Management, \\ Erasmus University Rotterdam, Rotterdam, The Netherlands
}

L. U. Biter

e-mail: u.biter@sfg.nl

G. Mannaerts

e-mail: g.mannaerts@sfg.nl

R. Luitwieler

Department of Anesthesiology, Sint Franciscus Gasthuis, Kleiweg 500, 3045 PM Rotterdam, The Netherlands

e-mail: r.luitwieler@sfg.nl

M. Castro Cabezas

Department of Internal Medicine, Sint Franciscus Gasthuis, Kleiweg 500, 3045 PM Rotterdam, The Netherlands

e-mail: m.castrocabezas@sfg.nl

\begin{abstract}
Background Obesity is associated with respiratory symp-
\end{abstract}
Kleiweg 500, 3045 PM Rotterdam, The Netherlands

G.-J. Braunstahl

L. U. Biter $\cdot$ G. Mannaerts

Department of Surgery, Sint Franciscus Gasthuis, 
complications: $\mathrm{FEV}_{1} / \mathrm{FVC}<70 \%$ adjusted OR 3.1 (95\%CI 1.4-6.8, $p=0.006)$ and $\Delta \mathrm{FEV}_{1} \geq 12 \%$ adjusted OR 2.9 (95\%CI 1.3-6.6, $p=0.010$ ).

Conclusions The risk of pulmonary complications after laparoscopic bariatric surgery is low. However, subjects with abnormal spirometry test results have a threefold risk of complications after laparoscopic bariatric surgery. Preoperative pulmonary function testing might be useful to predict the risk of complications of laparoscopic bariatric surgery.

Keywords Pulmonary function test · Morbid obesity . Obesity $\cdot$ Bariatric surgery $\cdot$ Complications

$\begin{array}{ll}\text { Abbreviations } \\ \text { ASA } & \text { American Society of Anesthesiologists } \\ \text { BMI } & \text { Body mass index } \\ \text { COPD } & \text { Chronic obstructive pulmonary disease } \\ \text { ESS } & \text { Epworth sleepiness scale } \\ \text { FeNO } & \text { Exhaled nitric oxide } \\ \text { FEV } & \text { Forced expiratory volume in } 1 \mathrm{~s} \\ \text { FRC } & \text { Functional respiratory capacity } \\ \text { FVC } & \text { Forced vital capacity } \\ \text { GERD } & \text { Gastroesophageal reflux disease } \\ \text { OSAS } & \text { Obstructive sleep apnea syndrome } \\ \text { RV } & \text { Residual volume } \\ \text { TLC } & \text { Total lung capacity }\end{array}$

\section{Introduction}

Obesity is becoming a worldwide epidemic. In 2008, the WHO estimated that one out of ten persons of the world's adult population was obese [1]. Accordingly, the number of bariatric surgery procedures being performed is increasing every year, with a 22-fold increase between 1996 and 2008 [2]. The postoperative morbidity rate after bariatric surgery is about $5 \%$. Gupta showed in a large cohort study that postoperative pneumonia and respiratory failure, despite being infrequent complications of bariatric surgery, account for one fifth of the morbidity. Moreover, these complications are also associated with increased mortality [3] and represent largest attributable costs of all complications [4]. The prevention of complications of bariatric surgery is of great importance, especially since the operation is elective and complications are difficult to treat in this group of morbidly obese patients. Obesity is found to be a risk factor for the development of postoperative pulmonary complications after abdominal surgery [5]. Obesity-related comorbidities may predispose obese patients to postoperative complications, as illustrated by the observation that asthma is $50 \%$ more prevalent among obese subjects [6] and obese asthma patients have worse asthma control [7], which might predispose them to postoperative complications.
Current guidelines do not indicate pulmonary function testing in patients without evidence of pre-existing lung disease who are evaluated for non-thoracic surgical procedures. It is, however, questionable whether this also holds true for the morbidly obese. Spirometry could identify patients who are at risk for complications, although this is not the current consensus [8]. Spirometry is mandatory in patients who are heavy smokers, or have complaints of dyspnea or cough [9]. However, there is a poor correlation between lung function measurements and the presence of symptoms [10], also among the morbidly obese.

Hamoui has shown that pulmonary function parameters prior to open bariatric surgery are predictive for complications after bariatric surgery [11]. However, bariatric surgery has developed during the last decade into a laparoscopic procedure which is considered to be a safer treatment than open surgery [12]. Laparoscopic procedures are typically associated with less postoperative pain, decreased opioid use, and earlier mobilization when compared with open procedures [13]. However, the prognostic added value of pulmonary function testing before laparoscopic bariatric surgery is unknown.

Since laparoscopic procedures are now standard, and little is known about the value of pulmonary function tests before laparoscopic bariatric surgery, we performed a prospective study to compare the predictive relationship between lung function parameters before laparoscopic bariatric surgery and the postoperative 30-days risk of complications, taking comorbidities, demographic, and anthropomorphic features into account. We hypothesized that abnormal lung function test results before surgery could identify patients at risk for complications of bariatric surgery.

\section{Materials and Methods}

Study Population

The subjects included in this study were consecutive patients who underwent a preoperative screening program for bariatric surgery in the Sint Franciscus Gasthuis in Rotterdam, the Netherlands, between October 2009 and November 2011. Eligibility criteria for bariatric surgery were: age between 18 and 60 years, body mass index (BMI) either $\geq 40$ or $\geq 35 \mathrm{~kg} / \mathrm{m}^{2}$ combined with the presence of comorbidity such as diabetes mellitus, hypertension or proven obstructive sleep apnea syndrome (OSAS). Prior to surgery, subjects underwent physical examinations that included routine assessment of anthropometry and pulmonary function. Height and weight were measured wearing light clothes and no shoes. Body mass index was calculated as weight (in kilogram) divided by height (in meter squared). 
Abdominal circumference was measured directly to the body surface midway between the lower rib margin and the ileac crest. Fat free mass and fat weight (in kilogram and percentage of body weight) were measured using electrical impedance analysis (Bodystat 1500, Bodystat Ltd, British Isles) [14]. The presence of comorbidities was defined as follows: diabetes mellitus, hypertension or hyperlipidemia all by the use of medication, the presence of the metabolic syndrome according to the NCEP-ATP-III criteria [15], the diagnosis of asthma and COPD after consultation with a pulmonologist and pulmonary function tests, as described below. The Epworth Sleepiness Scale [16] questionnaire was used to assess OSAS, and the GERD Questionnaire [17] for gastroesophageal reflux disease (GERD).

All participating subjects gave informed consent. The local ethics committee (Toetsingscommissie Wetenschappenlijk Onderzoek Rotterdam e.o, trial number NL25637.101.08) approved the study protocol (Netherlands Trial Register number NTR3204).

\section{Pulmonary Function Tests}

Spirometry was performed with Vmax spirometer (Vmax SensorMedics Viasys, type Encore 20/22/229/62 Encore, Cardinal Health, USA) before and after $400 \mu \mathrm{g}$ of inhaled salbutamol, with subjects in a sitting position and nose clips in place according to the American Thoracic Society/European Respiratory Society statement [18]. All values obtained were related to height, age, and gender and were expressed as percentage of their predicted value (reference ERS 1993). The pulmonary function test results are shown as prebronchodilator values unless otherwise indicated. The degree of reversibility in forced expiratory volume in $1 \mathrm{~s}\left(\mathrm{FEV}_{1}\right)$, which indicates a diagnosis of asthma is generally accepted as $\geq 12 \%$ and $200 \mathrm{ml}$ from the prebronchodilator value $\left(\Delta \mathrm{FEV}_{1} \geq 12 \%\right)$ [19]. Because many lung diseases may result in reduced $\mathrm{FEV}_{1}$, a useful assessment of airflow limitation is the ratio of $\mathrm{FEV}_{1}$ to $\mathrm{FVC}$. The $\mathrm{FEV}_{1} / \mathrm{FVC}$ ratio is normally greater than $70 \%$. Total lung capacity could only be measured if subjects were $<150 \mathrm{~kg}$. Exhaled nitric oxide (FeNO) was measured with Niox mino (Aerocrine, Sweden) and expressed in parts per billion (ppb) [20].

\section{Bariatric Surgery}

All operations were laparoscopic, either sleeve gastrectomy [21] or Roux-en Y gastric bypass. Routine anesthesia was applied with desflurane and remifentanil. Both procedures were performed with the patient in a semi-reclining position (anti-Trendelenburg position) with the legs in split upward position (French position). All patients routinely received prophylaxis against deep venous thrombosis with pneumatic compression stocking and subcutaneous low molecular weight heparin during two weeks. Perioperative antibiotics (cefazoline $2 \mathrm{~g}$ ) were also routinely given. Patients were normally discharged the second day after surgery.

\section{Complications}

The cumulative 30-days postoperative complications were obtained from the patient charts and divided into pulmonary, surgical, infectious, or other by a surgeon and a pulmonologist. The reasons for either hospital readmission or the problem found at relaparoscopy were scored as complications, but readmission or relaparoscopy itself were not scored as separate complications.

\section{Statistical Analyses}

Analysis was not restricted to pulmonary problems, but included all complications. Patients were divided into groups with and without complications. Unadjusted between-group comparisons were performed using Student's $t$ test or the Chi-square test (or Fisher's Exact test, where appropriate) and the Mann Whitney $U$ test for nonparametric comparisons. Multiple logistic regression analysis (entered) was used to assess the relationship between preoperative factors and the risk of postoperative complications adjusted for other co-variables. Baseline variables associated with complications in univariate analysis at a $p$ value of $<0.1$ were examined in the logistic regression analysis. Age, sex, BMI, and smoking status were added to the regression analysis. Since $\mathrm{FEV}_{1}$ and FVC are associated, we used three different regression models which all contained one of the pulmonary function parameters. All analyses were performed using SPSS 18.0 software (SPSS Inc., Chicago, Illinois, USA). A two-sided $p<0.05$ was considered a statistically significant result.

\section{Results}

Four hundred eighty-five patients were included (mean BMI $45.4 \mathrm{~kg} / \mathrm{m}^{2}, \mathrm{M} / \mathrm{F}$ 100:385). There were in total 53 complications in 50 patients $(10.3 \%)$ after bariatric surgery (as specified in Table 1). There were 35 readmissions (7.2\%), of which seven patients were found to have no complications. Relaparoscopy was performed in 16 cases, relaparotomy in 1 case (total $3.5 \%$ ). All of these subjects were found to have a complication (nine hematoma, one spleen injury, one anastomosis leakage, three anastomosis stenosis, two small bowel injuries, and one abscess). No deaths occurred. 
Table 1 Postoperative complications

\begin{tabular}{ll}
\hline & Frequency \\
\hline Pulmonary complications & $8(1.6 \%)$ \\
Pneumonia & 5 \\
Pulmonary embolism & 1 \\
Pneumothorax & 1 \\
Lung abscess & 1 \\
Surgical complications & $27(5.6 \%)$ \\
Hematoma (intra-abdominal) & 10 \\
Spleen injury & 3 \\
Anastomotic leak & 2 \\
Anastomotic stenosis & 3 \\
Requirement for blood transfusion & 4 \\
Small bowel injury & 2 \\
Abscess (deep) & 1 \\
Stenosis (endoscopic dilatation) & 1 \\
Hypovolemic shock & 1 \\
Infectious complications & 1 \\
Urinary tract infection & 1 \\
Abdominal wall infection & 3 \\
Unknown & 3 \\
Other complications & 1 \\
Dehydration & 1 \\
Intensive care admission for hyperglycaemia & 1 \\
\hline
\end{tabular}

Baseline characteristics did not differ between subjects with or without complications (Table 2), especially not in BMI, abdominal circumference or fat mass. The superobese patients $\left(\mathrm{BMI}>50 \mathrm{~kg} / \mathrm{m}^{2}, n=104\right)$ did not have more complications than the subjects with BMI $<50 \mathrm{~kg} / \mathrm{m}^{2}(n=381)$ ( $10.6 \%$ versus $10.2 \%, p=0.92$ ). There was no difference in pre-existing comorbidities, e.g., asthma, diabetes, reflux (assessed with GERD-Q), or sleep apnea syndrome (assessed with ESS). There were no differences either in operation technique used (sleeve gastrectomy or gastric bypass) or in American Society of Anesthesiologists (ASA) scoring between groups with or without complications. There was a trend towards longer operation duration in subjects with complications, and the median length of hospital stay was significantly longer in subjects with complications (Table 2).

Subjects with complications had a significantly lower $\mathrm{FEV}_{1}$ compared to subjects without complications (Table 3). Subjects with complications more often had airflow reversibility (increase in $\mathrm{FEV}_{1}$ after bronchodilatation of at least $12 \%$ ) and airway obstruction $\left(\mathrm{FEV}_{1} / \mathrm{FVC}<70 \%\right.$ predicted), compared to subjects without complications. There was no difference in TLC or FeNO between subjects with or without complications.

Abnormal spirometry requiring an intervention by means of additional medication, increased medication dose or preoperative steroid course occurred more often in subjects with complications $(26 \%)$ than in subjects without complications (14\%, $\%=0.026)$. Subjects with a medication advice did not have longer operation duration or length of hospital stay.

Table 4 displays the results of three separate logistic regression analyses, after adjustment for age, sex, BMI and smoking status. Since $\mathrm{FEV}_{1}$ and FVC are correlated, we used three different models which all contained one of the pulmonary function parameters. Airway reversibility $\left(\triangle \mathrm{FEV}_{1} \geq 12 \%\right)$ and airway obstruction $\left(\mathrm{FEV}_{1} / \mathrm{FVC}\right.$ $<70 \%$ ) remained significant predictors of complications.

\section{Discussion}

This study demonstrates that morbidly obese subjects with abnormal preoperative spirometric results-more specifically, airway obstruction $\left(\mathrm{FEV}_{1} / \mathrm{FVC}<70 \%\right.$ predicted) (adjusted OR 3.1) or airflow reversibility (increase of $\mathrm{FEV}_{1} \geq 12 \%$ ) (adjusted OR 2.9) - are more likely to develop postoperative complications after undergoing laparoscopic bariatric surgery.

To our knowledge, this is the first study which has investigated the association between preoperative pulmonary function testing and complications after laparoscopic bariatric surgery. Previous studies have investigated complications in open procedures [10] or both open and laparoscopic [22]. Furthermore, this study has also included sleeve gastrectomy, a rather new surgical technique as a standalone procedure. This study has used a large group of subjects, who were all well characterized.

The American Society for Metabolic and Bariatric Center of Excellence facilities report mentioned a $5 \%$ readmission rate and a $2 \%$ reoperation rate [23], which compares well with our rates ( $7 \%$ and $3.5 \%$ respectively). Also, our complication rate of $10 \%$ is comparable to other studies (3 to $24 \%$ ). Surgical experience may have influenced the complication rates. Some studies suggest that leakage is more likely to occur when the surgeon is less experienced [24]. In the present study, procedures were performed by an experienced team in which each surgeon had carried out over 200 procedures. Furthermore, the highly standardized treatment protocol applied in our hospital, such as routine prophylaxis against deep venous thrombosis with pneumatic compression stocking and administration of subcutaneous heparin, probably also prevented complications.

There is considerable debate regarding the role of preoperative pulmonary function testing for risk stratification. It has been suggested that the test simply confirms the clinical impression of disease severity in most cases, adding little to the clinical estimation of risk of complications [25]. Consequently, most patients with an abnormal spirometry test 
Table 2 Baseline characteristics of subjects
Unless stated otherwise, data presented as mean \pm standard deviation or percentage

$O S A S$ obstructive sleep apnea syndrome, GERD gastroesophageal reflux disease, ASA score American Society of Anesthesiologists score

${ }^{\mathrm{a}}$ Data presented as median (IQR)

\begin{tabular}{|c|c|c|c|}
\hline & $\begin{array}{l}\text { Subjects without complications } \\
N=435\end{array}$ & $\begin{array}{l}\text { Subjects with complications } \\
N=50\end{array}$ & $p$ value \\
\hline Age (years) & $41.6 \pm 11.1$ & $40.7 \pm 10.8$ & 0.603 \\
\hline Weight (kg) & $131.0 \pm 22.4$ & $136.1 \pm 28.5$ & 0.229 \\
\hline Body mass index $\left(\mathrm{kg} / \mathrm{m}^{2}\right)$ & $45.3 \pm 6.2$ & $46.5 \pm 6.6$ & 0.196 \\
\hline Abdominal circumference $(\mathrm{cm})$ & $131.6 \pm 14.9$ & $133.1 \pm 17.0$ & 0.536 \\
\hline \multicolumn{4}{|l|}{ Bioimpedance } \\
\hline Fat free mass $(\mathrm{kg})$ & $63.78 \pm 11.2$ & $66.4 \pm 14.4$ & 0.164 \\
\hline Fat $(\%)$ & $50.5 \pm 7.0$ & $51.4 \pm 6.9$ & 0.425 \\
\hline Fat (kg) & $66.9 \pm 16.3$ & $71.2 \pm 18.9$ & 0.117 \\
\hline Gender ( $\%$ female $)$ & $79.5 \%$ & $78.0 \%$ & 0.799 \\
\hline Ethnicity (\% Caucasian) & $84.6 \%$ & $86.0 \%$ & 0.475 \\
\hline Smoking status & & & 0.758 \\
\hline$\%$ Never & $42 \%$ & $46 \%$ & \\
\hline$\%$ Former & $33 \%$ & $28 \%$ & \\
\hline$\%$ Active & $25 \%$ & $26 \%$ & \\
\hline Pack years $^{\mathrm{a}}$ & $2.2(0-12.5)$ & $2.2(0-14)$ & 0.754 \\
\hline \multicolumn{4}{|l|}{ Comorbidity } \\
\hline Asthma & $23.0 \%$ & $28.0 \%$ & 0.429 \\
\hline COPD & $3.2 \%$ & $2.0 \%$ & 0.999 \\
\hline Diabetes mellitus & $32.0 \%$ & $33.3 \%$ & 0.856 \\
\hline Hypertension & $74.4 \%$ & $68.8 \%$ & 0.396 \\
\hline Hypercholesterolemia & $35.8 \%$ & $43.8 \%$ & 0.281 \\
\hline Metabolic syndrome & $64.6 \%$ & $64.6 \%$ & 0.993 \\
\hline Epworth sleepiness scale (OSAS) $^{\mathrm{a}}$ & $3(2-4)$ & $3(1-4)$ & 0.870 \\
\hline GERD questionnaire & $6.9 \pm 2.3$ & $6.4 \pm 1.9$ & 0.455 \\
\hline \multicolumn{4}{|l|}{ Surgery } \\
\hline Operation (\% sleeve gastrectomy) & $63 \%$ & $58 \%$ & 0.470 \\
\hline Operation duration (min) & $92.4 \pm 40.4$ & $102.9 \pm 37.2$ & 0.080 \\
\hline Admission (days) ${ }^{\mathrm{a}}$ & $4(3-4)$ & $5(4-7.25)$ & $<0.001$ \\
\hline ASA scoring & & & 0.835 \\
\hline $1(\%)$ & $0.2 \%$ & $0 \%$ & \\
\hline $2(\%)$ & $36.8 \%$ & $34.1 \%$ & \\
\hline $3(\%)$ & $60.5 \%$ & $61.4 \%$ & \\
\hline $4(\%)$ & $2.4 \%$ & $4.5 \%$ & \\
\hline
\end{tabular}

result would also have been identified on the basis of history and physical examination. Several critical remarks can be made. First, lung function measurements and the presence of symptoms are poorly associated [10]. Second, all studies on the added value of preoperative spirometry were conducted in a general population, and not in the specific morbidly obese patient group undergoing bariatric surgery, as described here. Since the morbidly obese can be seen as a distinct group with a different physiology, it is questionable whether results from the general population also apply to the obese. One exception is Gonzalez et al. who investigated the role of pulmonary function testing specifically in the morbidly obese. They found that a $\mathrm{FEV}_{1}<80 \%$ of predicted increased the likelihood of complicated postoperative management after Roux-en-Y gastric bypass [21]. They combined open and laparoscopic operations, whereas we only used the laparoscopic technique. Although the current study does not support the data by Gonzalez et al, a similar trend was found here (OR 1.9, $p=0.07$, Table 4). However, our study found that $\mathrm{FEV}_{1} / \mathrm{FVC}<70 \%$ (airflow obstruction) and $\triangle \mathrm{FEV}_{1}>12 \%$ (airflow reversibility) increased the likelihood of complicated bariatric surgery.

Airflow reversibility and airflow obstruction are hallmarks of asthma. Valid comparisons with other studies are limited. Other publications on the risk of complications of bariatric surgery did not include asthma [3], or state that well-controlled asthma is not a risk factor [8]. Although the diagnosis of asthma is usually based on the presence of 
Table 3 Pulmonary function tests

\begin{tabular}{|c|c|c|c|c|}
\hline & $N$ & Subjects without complications & Subjects with complications & $p$ value \\
\hline $\mathrm{FEV}_{1}(\%$ predicted $)$ & 485 & $92.9 \pm 14.3$ & $86.9 \pm 13.5$ & 0.005 \\
\hline $\mathrm{FEV}_{1}<80 \%$ predicted & 485 & $17.1 \%$ & $28.0 \%$ & 0.057 \\
\hline FVC (\% predicted) & 485 & $100.1 \pm 14.9$ & $95.7 \pm 13.0$ & 0.045 \\
\hline FVC $<80 \%$ predicted & 485 & $9.0 \%$ & $10.0 \%$ & 0.813 \\
\hline $\mathrm{FEV}_{1} / \mathrm{FVC}(\%$ predicted $)$ & 485 & $79.2 \pm 5.9$ & $77.7 \pm 7.8$ & 0.111 \\
\hline RV (\% predicted, post) & 212 & $76.9 \pm 20.4$ & $76.5 \pm 14.3$ & 0.941 \\
\hline FRC (\% predicted, post) & 212 & $66.0 \pm 13.2$ & $66.1 \pm 12.3$ & 0.993 \\
\hline TLC (\% predicted, post) & 212 & $94.8 \pm 11.2$ & $95.2 \pm 8.4$ & 0.889 \\
\hline Reversibility $\mathrm{FEV}_{1}(\%)$ & 485 & $4.3 \pm 4.9$ & $5.5 \pm 7.7$ & 0.315 \\
\hline $\mathrm{FeNO}(\mathrm{ppb})^{\mathrm{a}}$ & 225 & $14.5(9.0-22.0)$ & $17.0(9.5-23.5)$ & 0.676 \\
\hline$\Delta \mathrm{FEV}_{1} \geq 12 \%$ & 485 & $7.2 \%$ & $18.4 \%$ & 0.007 \\
\hline $\mathrm{FEV}_{1} / \mathrm{FVC}<70 \%$ predicted & 485 & $8.1 \%$ & $20.0 \%$ & 0.006 \\
\hline
\end{tabular}

Unless stated otherwise, data presented as mean \pm standard deviation or percentage

${ }^{\text {a }}$ Data presented as median (IQR)

$F E V_{l}$ forced expiratory volume in $1 \mathrm{~s}, F V C$ forced vital capacity, $R V$ residual volume, $F R C$ functional respiratory capacity, $T L C$ total lung capacity, $\mathrm{FeNO}$ exhaled nitric oxide

characteristic symptoms, in the morbidly obese, these symptoms are often unreliable [26]. It is known that asthma is overdiagnosed by $30 \%$ when self-reported asthma is used [27]. The European Respiratory Society state in the Global Initiative for Asthma guidelines that the measurement of reversibility of lung function abnormalities greatly enhances diagnostic confidence, and it also recommends that patients with asthma undergo preoperative evaluation to assess asthma control [18]. We advocate that spirometry should be part of preoperative evaluation before bariatric surgery for the following three reasons. First of all, this is because asthma is $50 \%$ more prevalent among obese subjects [6], and obesity is an important risk factor for severe asthma [7]. Secondly, the diagnosis of asthma is more complicated in obese subjects than in lean subjects. Finally, our results show that spirometric tests can identify the patients at risk for complications.

Interestingly, our study has shown that spirometry is not only useful in predicting pulmonary complications, but it might predict all complications of bariatric surgery. This it is in line with previous findings that $\mathrm{FEV}_{1}$ is associated with mortality [28-30]. $\mathrm{FEV}_{1}$ could possibly be a marker of general health or fitness. So abnormal spirometry does not only indicate obstructive pulmonary disease, but might also indicate poor general health. In contrast to spirometry, the American Society of Anesthesiologists physical status scale

Table 4 Multivariable logistic regression analysis of the risk of complications after laparoscopic bariatric surgery

\begin{tabular}{|c|c|c|c|c|c|c|c|c|c|}
\hline & \multicolumn{3}{|l|}{ Model I } & \multicolumn{3}{|l|}{ Model II } & \multicolumn{3}{|c|}{ Model III } \\
\hline & $\operatorname{Exp}(\mathrm{B})$ & $95 \% \mathrm{CI}$ & $p$ value & Exp (B) & $95 \% \mathrm{CI}$ & $p$ value & $\operatorname{Exp}(\mathrm{B})$ & $95 \% \mathrm{CI}$ & $p$ value \\
\hline Age & 0.992 & $0.966-1.019$ & 0.558 & 0.990 & $0.964-1.017$ & 0.466 & 0.992 & $0.965-1.019$ & 0.548 \\
\hline Sex & 0.903 & $0.443-1.843$ & 0.780 & 1.045 & $0.504-2.171$ & 0.905 & 0.892 & $0.434-1.832$ & 0.755 \\
\hline BMI & 1.028 & $0.982-1.076$ & 0.238 & 1.032 & $0.986-1.081$ & 0.176 & 1.018 & $0.970-1.068$ & 0.469 \\
\hline Smoking status ${ }^{\mathrm{a}}$ & 1.017 & $0.515-2.010$ & 0.961 & 0.958 & $0.480-1.915$ & 0.904 & 1.063 & $0.535-2.112$ & 0.861 \\
\hline Constant & 0.043 & & 0.015 & 0.034 & & 0.011 & 0.068 & & 0.051 \\
\hline $\mathrm{FEV}_{1}<80 \%$ predicted & 1.865 & $0.953-3.652$ & 0.069 & & & & & & \\
\hline $\mathrm{FEV}_{1} / \mathrm{FVC}<70 \%$ predicted & & & & 3.057 & $1.370-6.823$ & 0.006 & & & \\
\hline$\Delta \mathrm{FEV}_{1} \geq 12 \%$ & & & & & & & 2.933 & $1.298-6.629$ & 0.010 \\
\hline
\end{tabular}

All models consisted of the variables age, sex, BMI and smoking status. Since $\mathrm{FEV}_{1}$ and FVC are associated, we used three different regression models which all contained one of the pulmonary function parameters. Model I added $\mathrm{FEV}_{1}<80 \%$ predicted as variable, model II added $\mathrm{FEV}_{1} / \mathrm{FVC}<70 \%$ predicted as variable, and model III added $\Delta \mathrm{FEV}_{1} \geq 12 \%$ as variable

${ }^{\text {a }}$ Current smokers versus rest

$F E V_{l}$ forced expiratory volume in $1 \mathrm{~s}, F V C$ forced vital capacity 
(ASA) appeared to be insensitive for predicting complications in this study.

Another study suggested that the super obese (BMI $>50 \mathrm{~kg} / \mathrm{m}^{2}$ ) are more prone to complications of bariatric surgery [31]. This study did not find this relationship in our cohort, despite the fact that $21 \%$ had a BMI $>50 \mathrm{~kg} / \mathrm{m}^{2}$. Furthermore, this study found no difference in mean BMI, body fat percentage, or abdominal circumference between the subjects with and without complications. Therefore, this study does not support that differences in fat distribution influence the risk of complications of bariatric surgery.

Cawley and coworkers in a large cohort study showed that subjects with obesity-related comorbidities prior to bariatric surgery were at significantly elevated risk of postsurgery complications [32]. In contrast, in our cohort presurgical obesity-related comorbidities such as diabetes mellitus, hypertension, hyperlipidemia, GERD or OSAS were unrelated to complications. This might be an effect of the extensive presurgical screening - and if indicated treatment - for comorbidities as is standard in our hospital [33].

There are several limitations. First of all, complications were obtained from the patient charts, and may have been subject to underreporting. Secondly, we did not perform methacholine provocation tests, implying that a definite diagnosis of asthma could not always be reached. Finally, we did not perform a randomized study, so we cannot state anything on the surplus value of spirometry. Furthermore, the extensive presurgical screening program as incorporated in our hospital could have reduced the incidence of complications. The low numbers of pulmonary complications in our study did not allow for specific subgroup comparisons.

As symptoms are often unreliable in the morbidly obese, pulmonary function tests should routinely be part of the preoperative risk assessment. We have shown that subjects with complications within 30 days of bariatric surgery more often have airflow reversibility or airflow obstruction. Generally, laparoscopic bariatric surgery is safe, but randomized prospective studies are needed to investigate whether abnormal pulmonary functions tests could indeed serve as a guide in patient selection and optimization of the preoperative medical condition of patients undergoing bariatric surgery, which could lead to additional improvement in the outcomes after bariatric surgery.

Acknowledgements We wish to thank Mrs. Sandra Reijnhart for editing the manuscript. We are grateful for the help of all the staff in the Respiratory Laboratory and members of the Bariatric Surgery Team at Sint Franciscus Gasthuis.

Conflict of interest All authors declare no conflict of interest. This research was supported by grants from Foundation Research and Development Department of Internal Medicine Sint Franciscus Gasthuis (Stichting Onderzoek en Ontwikkeling Interne Specialismen Sint Franciscus Gasthuis).

\section{References}

1. Organisation WH. Obesity and overweight Fact Sheet no. 311. 2011. http://www.who.int/mediacentre/factsheets/fs311/en/ index.html. Accessed 5 Dec 2012.

2. Buchwald H, Oien DM. Metabolic/bariatric surgery worldwide 2008. Obes Surg. 2009;19(12):1605-11.

3. Gupta PK, Gupta H, Kaushik M, et al. Predictors of pulmonary complications after bariatric surgery. Surg Obes Relat Dis. 2011;8(5):574-81.

4. Dimick JB, Chen SL, Taheri PA, et al. Hospital costs associated with surgical complications: a report from the private-sector National Surgical Quality Improvement Program. J Am Coll Surg. 2004;199(4):531-7.

5. Brooks-Brunn JA. Predictors of postoperative pulmonary complications following abdominal surgery. Chest. 1997;111(3):564-71.

6. Beuther DA, Sutherland ER. Overweight, obesity, and incident asthma: a meta-analysis of prospective epidemiologic studies. Am J Respir Crit Care Med. 2007;175(7):661-6.

7. Mosen DM, Schatz M, Magid DJ, et al. The relationship between obesity and asthma severity and control in adults. J Allergy Clin Immunol. 2008;122(3):507-11. e6.

8. Smetana GW. Postoperative pulmonary complications: an update on risk assessment and reduction. Cleve Clin J Med. 2009;76 Suppl 4:S60-5.

9. Chetta A, Tzani P, Marangio E, et al. Respiratory effects of surgery and pulmonary function testing in the preoperative evaluation. Acta Biomed. 2006;77(2):69-74.

10. Kerstjens HA, Brand PL, de Jong PM, et al. Influence of treatment on peak expiratory flow and its relation to airway hyperresponsiveness and symptoms. The Dutch CNSLD Study Group. Thorax. 1994;49(11):1109-15.

11. Hamoui N, Anthone G, Crookes PF. The value of pulmonary function testing prior to bariatric surgery. Obes Surg. 2006;16(12):1570 3.

12. Reoch J, Mottillo S, Shimony A, et al. Safety of laparoscopic vs open bariatric surgery: a systematic review and meta-analysis. Arch Surg. 2011;146(11):1314-22.

13. Davis G, Patel JA, Gagne DJ. Pulmonary considerations in obesity and the bariatric surgical patient. Med Clin North Am. 2007;91(3):433-42. xi.

14. Fuller NJ, Sawyer MB, Elia M. Comparative evaluation of body composition methods and predictions, and calculation of density and hydration fraction of fat-free mass, in obese women. Int J Obes Relat Metab Disord. 1994;18(7):503-12.

15. Grundy SM, Brewer Jr HB, Cleeman JI, et al. Definition of metabolic syndrome: report of the national heart, lung, and blood institute/american heart association conference on scientific issues related to definition. Circulation. 2004;109(3):433-8.

16. Johns MW. A new method for measuring daytime sleepiness: the Epworth sleepiness scale. Sleep. 1991;14(6):540-5.

17. Jones R, Junghard O, Dent J, et al. Development of the GerdQ, a tool for the diagnosis and management of gastro-oesophageal reflux disease in primary care. Aliment Pharmacol Ther. 2009;30(10):1030-8.

18. Miller MR, Hankinson J, Brusasco V, et al. Standardisation of spirometry. Eur Respir J. 2005;26(2):319-38.

19. Bateman ED, Hurd SS, Barnes PJ, et al. Global strategy for asthma management and prevention: GINA executive summary. Eur Respir J. 2008;31(1):143-78.

20. American Thoracic Society, European Respiratory Society. ATS/ ERS recommendations for standardized procedures for the online and offline measurement of exhaled lower respiratory nitric oxide and nasal nitric oxide, 2005. Am J Respir Crit Care Med. 2005;171(8):912-30. 
21. Gadiot RP, Biter LU, Zengerink HJ, et al. Laparoscopic sleeve gastrectomy with an extensive posterior mobilization: technique and preliminary results. Obes Surg. 2012;22(2):320-9.

22. Gonzalez R, Bowers SP, Venkatesh KR, et al. Preoperative factors predictive of complicated postoperative management after Roux-en-Y gastric bypass for morbid obesity. Surg Endosc. 2003;17(12):1900-4.

23. Pratt GM, Learn CA, Hughes GD, et al. Demographics and outcomes at American Society for Metabolic and Bariatric Surgery Centers of Excellence. Surg Endosc. 2009;23(4):795-9.

24. Schauer P, Ikramuddin S, Hamad G, et al. The learning curve for laparoscopic Roux-en-Y gastric bypass is 100 cases. Surg Endosc. 2003;17(2):212-5.

25. Smetana GW, Lawrence VA, Cornell JE. Preoperative pulmonary risk stratification for noncardiothoracic surgery: systematic review for the American College of Physicians. Ann Intern Med. 2006;144(8):581-95.

26. Babb TG, Ranasinghe KG, Comeau LA, et al. Dyspnea on exertion in obese women: association with an increased oxygen cost of breathing. Am J Respir Crit Care Med. 2008;178(2):116-23.

27. Aaron SD, Vandemheen KL, Boulet LP, et al. Overdiagnosis of asthma in obese and nonobese adults. Cmaj. 2008;179(11):1121-31.
28. Young RP, Hopkins R, Eaton TE. Forced expiratory volume in one second: not just a lung function test but a marker of premature death from all causes. Eur Respir J. 2007;30(4):616-22.

29. Schunemann HJ, Dorn J, Grant BJ, et al. Pulmonary function is a long-term predictor of mortality in the general population: 29-year follow-up of the Buffalo Health Study. Chest. 2000;118(3):65664.

30. Sin DD, Wu L, Man SF. The relationship between reduced lung function and cardiovascular mortality: a population-based study and a systematic review of the literature. Chest. 2005;127(6):19529 .

31. Arterburn D, Livingston EH, Schifftner T, et al. Predictors of longterm mortality after bariatric surgery performed in Veterans Affairs medical centers. Arch Surg. 2009;144(10):914-20.

32. Cawley J, Sweeney MJ, Kurian M, et al. Predicting complications after bariatric surgery using obesity-related co-morbidities. Obes Surg. 2007;17(11):1451-6.

33. Elte JW, Castro Cabezas M, Vrijland WW, et al. Proposal for a multidisciplinary approach to the patient with morbid obesity: the St. Franciscus Hospital morbid obesity program. Eur J Intern Med. 2008;19(2):92-8. 